\title{
Effect of salinity gradients on the distribution of phytoplankton pigments in a stratified estuary
}

\author{
M. Ahel ${ }^{1, *}$, R. G. Barlow ${ }^{2}$, R. F. C. Mantoura ${ }^{2}$ \\ 'Center for Marine Research-Division Zagreb, Ruder Bošković Institute, PO Box 1016, HR-10000 Zagreb, Croatia \\ ${ }^{2}$ Plymouth Marine Laboratory, Prospect Place, West Hoe, Plymouth PL1 3DH, United Kingdom
}

\begin{abstract}
Chlorophyll and carotenoid pigments were determined in the highly stratified Krka estuary, eastern Adriatic Sea, in order to study the distribution of phytoplankton during a spring bloom. Both axial and vertical profiles of pigment concentrations revealed the dynamic nature of the phytoplankton in terms of quantity, community structure and physiological status and were closely related to the salinity gradients in the estuary. Maximum concentrations of chlorophyll a (chl a) were found in the brackish layer of the lower part of the estuary, which received additional nutrient inputs via untreated sewage from the town of Sibenik, Croatia, eastern Adriatic coast. By contrast, the underlying saline layer contained significantly lower levels of chl a. Detailed depth profiles revealed that the concentration maxima of both chl $a$ $\left(8.5 \mathrm{\mu g}^{-1}\right)$ and its breakdown product phaeophorbide $a$ $\left(18 \mu \mathrm{g} \mathrm{I}^{-1}\right)$ occurred at the upper part of the halocline $(1.5 \mathrm{~m})$ This indicated that the interface of the brackish water/seawater layers was very efficient in collecting living and detrital particles from the highly productive brackish water layer, thus playing an important role in determining the distribution. and fate of organic matter in the estuary.
\end{abstract}

KEY WORDS: Pigment biomarkers - Phytoplankton - Stratified estuary - Salinity gradients

Estuaries are areas of the most intensive exchange of matter and energy between the continents and oceans and represent, therefore, biologically very dynamic environments. Sharp gradients in physico-chemical properties occurring in estuaries at the freshwater/seawater interface have been shown to cause dramatic changes in the distribution of non-conservative constituents such as oxygen, carbon, nutrients and trace metals (Morris et al. 1978, Mantoura 1987, Žutić \& Legovic 1987) and these gradients have an immense impact on the biology of estuaries, particularly the composition of phytoplankton. Both freshwater and marine organisms have been shown to respond

·E-mail: ahel@olimp.irb.hr strongly to salinity gradients, and a boundary at 4-7 PSU was identified as a critical region of physiological stress for freshwater species (Kinne 1971).

In open ocean studies, the use of chlorophyll and carotenoid biomarkers has proved to be especially useful in providing additional information concerning the chemotaxonomic composition of phytoplankton (Gieskes \& Kraay 1986, Bidigare et al. 1990), group specific distribution of phytoplankton biomass (Everitt et al. 1990, Barlow et al. 1993a), as well as degradation pathways of photosynthetic pigments (Barlow et al. 1993b, Head et al. 1994). However, only a limited number of such studies have been conducted in estuarine and coastal waters (Klein \& Sournia 1987, Roy 1989, Denant et al. 1991, Bianchi et al. 1993), mostly on vertically well-mixed macrotidal estuaries, and only a few have dealt with microtidal estuaries characterized by vertical salinity gradients (Denant et al. 1991)

The aim of the present work, therefore, was to investigate the origin and fate of phytoplankton biomass in a stratified estuary during a spring bloom by using pigments as biomarkers. We also demonstrate the importance of studying such an estuarine region, as it provides a further understanding of the environmental factors that influence dynamics of phytoplankton in neritic environments.

Materials and methods. The Krka River is a karstic river that enters the Adriatic Sea on its eastern coast (Fig. 1). It forms a $25 \mathrm{~km}$ long estuary of a salt wedge type that is preceded by a series of waterfalls and travertine barriers. The depth of the estuary gradually increases from $2 \mathrm{~m}$ below the waterfalls to $42 \mathrm{~m}$ near the estuary mouth. The freshwater flow varies between 20 and $170 \mathrm{~m}^{3} \mathrm{~s}^{-1}$, with an average of $55 \mathrm{~m}^{3} \mathrm{~s}^{-1}$. The average tidal amplitude is only 20 to $30 \mathrm{~cm}$. Due to the extremely low tidal range, the estuary is stratified throughout the whole year and consists of 2 fun- 

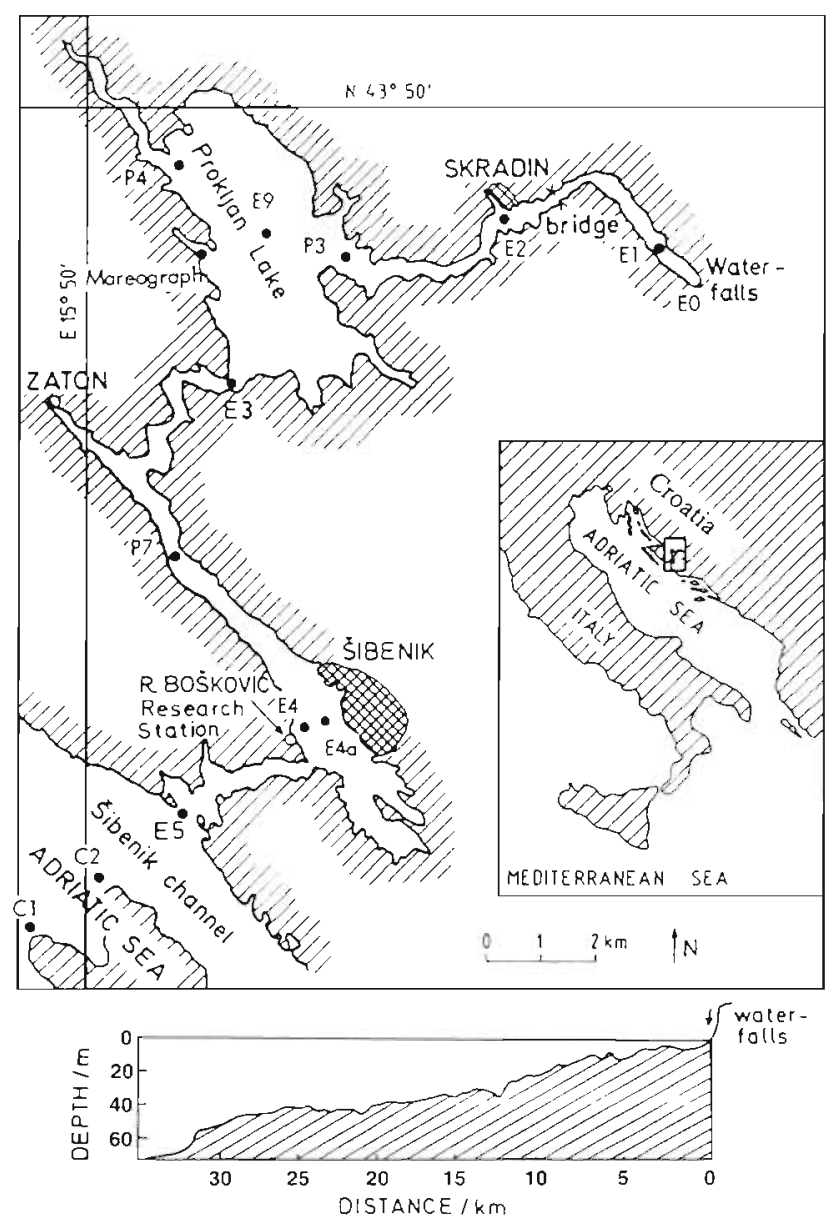

Chlorophyll and carotenoid pigments were determined according to the reverse-phase HPLC method as modified by Mantoura \& Llewellyn (1983) (see Barlow et al. 1993a). Briefly, water samples (2 1) were filtered through $47 \mathrm{~mm}$ Whatman GF/F filters and immediately frozen $\left(-20^{\circ} \mathrm{C}\right)$ until analysed. Storage at $-20^{\circ} \mathrm{C}$ was not quite good enough to prevent partial breakdown of chlorophyll a (chl a). Up to $10 \%$ of chl a was degraded to chl a allomer. Frozer. filters were extracted in 4 to $10 \mathrm{ml} 90 \%$ acetone using sonication and centrifuged to remove cellular debris. An aliquot $(300 \mu l)$ of clarified extract was mixed with $300 \mu \mathrm{l}$ of $1 \mathrm{M}$ ammonium acetate, and $100 \mu \mathrm{l}$ was injected in a Shimadzu HPLC system (dual LC-6A pumps, SPD-6AV spectrophotometric detector, SCL-6B system controller) equipped with a reverse-phase $3 \mu C_{18}$ column (Pecosphere, $35 \times$ $4.5 \mathrm{~mm}$, Perkin Elmer). Solvent A consisted of $80 \%$ methanol and $20 \% 1 \mathrm{M}$ ammonium acetate and solvent B contained $60 \%$ methanol and $40 \%$ acetone. Pigments were separated by a linear gradient from $0 \% \mathrm{~B}$ to $100 \%$ $\mathrm{B}$ for $10 \mathrm{~min}$, followed by an isocratic hold at $100 \% \mathrm{~B}$ for

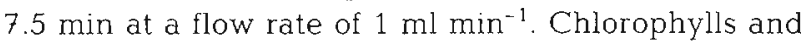
carotenoids were detected by absorbance at $440 \mathrm{~nm}$, while detection of phaeopigments was performed with a Perkin Elmer LS1 fluorescence detector using an excitation wavelength of $400( \pm 20) \mathrm{nm}$ and emission at $>600 \mathrm{~nm}$. For dual channel data collection and integration the Philips PU6000 software was utilized. Pigments were identified and quantified according to Barlow et al. (1993a).

Fig. 1 Krka estuary, eastern Adriatic, and sampling stations

damentally different compartments (Žutić \& Legovic 1987). The upper layer (0.2 to $4 \mathrm{~m}$ ), which is fresh or brackish, is characterized by relatively high primary production rates and ow residence time, while the underlying saline water layer is characterized by longer retention time and significantly lower production rates. The 2 zones are separated by a narrow interfacial layer with a sharp salinity gradient of up to 30 PSU per $20 \mathrm{~cm}$. Both layers are characterised by very low suspended matter concentrations which do not exceed $10 \mathrm{mg} \mathrm{l}^{-1}$ (Legović et al. 1994).

Water samples were drawn at various stations along the estuary (Fig. 1) during 14 and 15 March 1991 using standard Niskin bottles. The axial profiles of salinity, temperature, dissolved oxygen, silicate, nitrate and phosphate obtained during the field experiment are presented in Fig. 2 (Žutić \& Legović 1993).
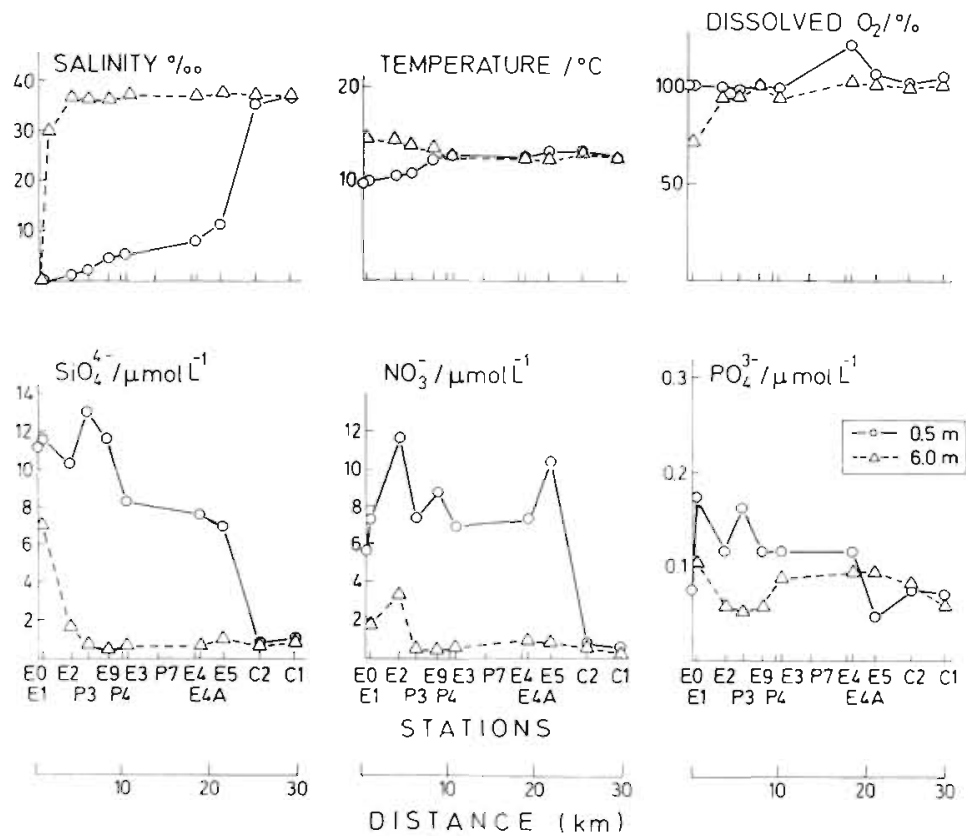

Fig. 2. Axıal profiles of the key hydrographic variables of the Krka estuary on March 14 and 15, 1991. Distances (km) refer to the position of sampling stations from the head of the estuary (see Fig. 1) 

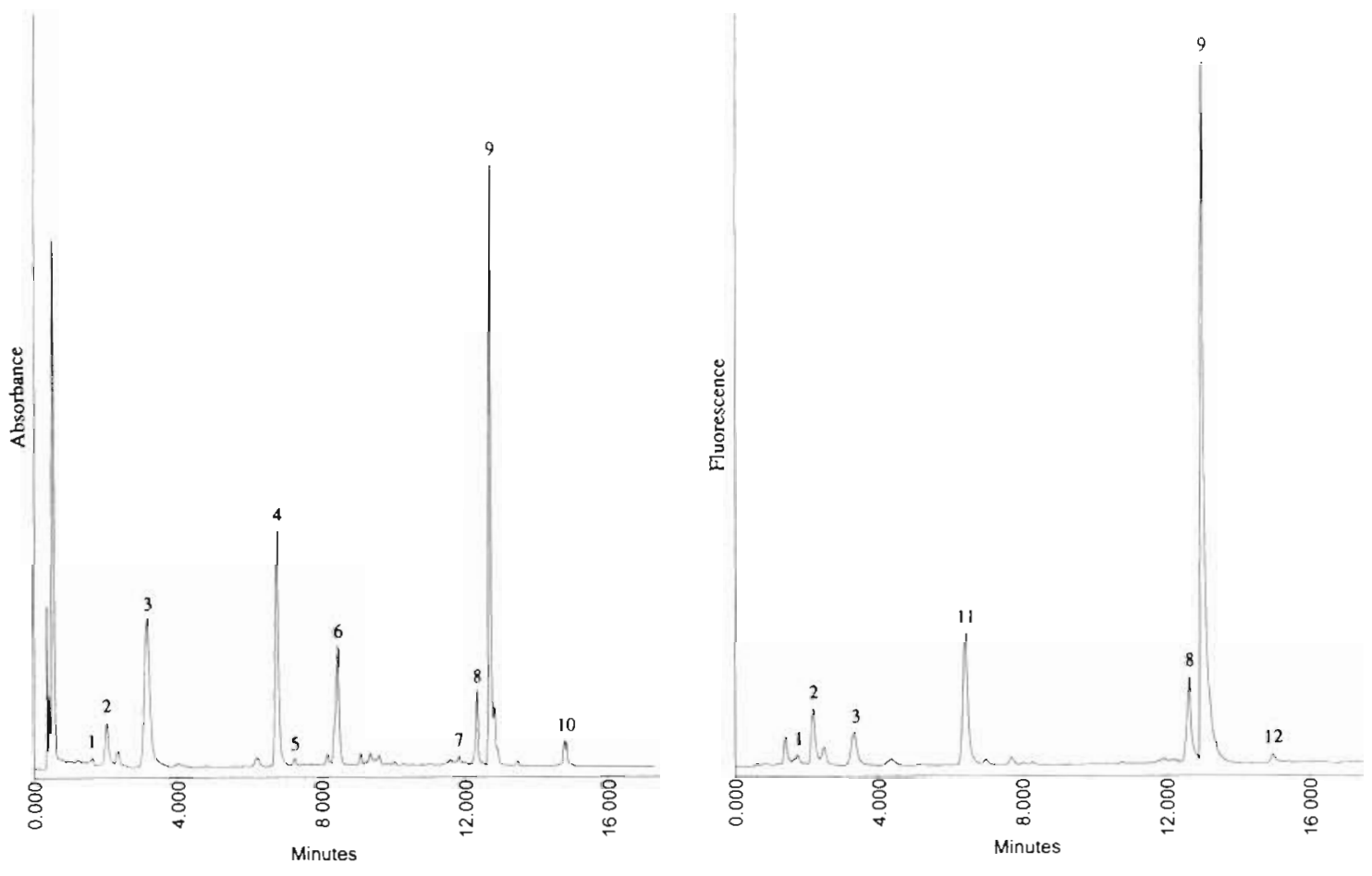

Fig. 3. HPLC absorbance $(440 \mathrm{~nm})$ and fluorescence chromatograms of a sample obtained on March 14 from the brackish layer of the Krka estuary (Stn E4A). Pigment identities are (1) chl $c_{3},(2)$ chlorophyllide $a_{1}(3)$ chl $c_{1}+c_{2}$, (4) fucoxanthin, (5) 19'-hexanoyloxyfucoxanthin, (6) diadinoxanthin, (7) chl b, (8) chlorophyll a allomer, (9) chl a, (10) $\beta$-carotene, (11) phaeophorbide a and (12) phaeophytin a

Results. An example of HPLC pigment chromatograms obtained by absorbance and fluorescence detection is shown in Fig 3. The absorbance chromatogram (Fig. 3) shows that fucoxanthin (Fuc) and diadinoxanthin were the most prominent carotenoids in both the brackish and saline water. Other important biomarkers were 19'-hexanoyloxyfucoxanthin (Hex) and chlorophyll $b$ (chl $b$ ), while only traces $\left(<10 \mathrm{ng}^{-1}\right.$ ) of peridinin and zeaxanthin/lutein were detected in the samples. The chromatogram obtained using fluorescence detection (Fig. 3) shows a significant presence of 4 main breakdown products of chl a: chlorophyllide $a_{1}$ phaeophorbide $a$, pyrophaeophorbide and phaeophytin $a$. The most prominent degradation product in the analysed samples was phaeophorbide $a$.

The axial profiles of selected pigment concentrations in brackish and saline water are presented in Fig. 4. The chl a levels in brackish water $\left(1.8\right.$ to $4.3 \mathrm{\mu g}^{-1}$ ) were significantly greater than those in the saline layer (0.7 to $1.2 \mu \mathrm{g} \mathrm{l}^{-1}$ ), except at the very end of the salt wedge ( 0 to $3.7 \mathrm{~km}$ from the waterfalls). In that part of the estuary, the maximum depth was only $4 \mathrm{~m}$ and the salinity of the saline layer was significantly reduced (Fig. 2), indicating considerable mixing with freshwater. In the brackish water, concentration maxima were observed at both the freshwater end and the marine end of the estuary, while the lowest concentrations were determined in the middle section (Fig. 4a). Enhanced chl a concentrations in the lower part of the estuary are caused by additional input of nutrients via wastewaters which enter Sibenik Harbour in the vicinity of Stn E4A (Fig. 1)

The axial changes in fucoxanthin levels (Fig. 4b) closely match those of chl $a$ in both the brackish water and saline layers, indicating the predominance of diatoms throughout the entire estuary. The chl a:Fuc ratio (weight:weight) varied from 2.6 to 4.3 in brackish water and from 2.7 to 3.3 in saline water. These ratios are much higher than those reported in the literature for diatom cultures (Hager \& Stransky 1970), and the difference cannot be explained by a contribution of chl a associated with other phytoplankton groups. The concentrations of chl $b$ and Hex along the estuary were markedly lower (Fig 4c) than those observed for Fuc, suggesting that contributions of green algae and prymnesiophytes to the total phytobiomass were low. Moreover, a comparison between the concentration profiles of Fuc, chl $b$ and Hex suggested that the various phytoplankton groups responded differently to salinity gradients and nutrient inputs in the Krka estuary. The levels of Fuc and chl $b$ in the brackish layer were usually significantly higher than in the saline 

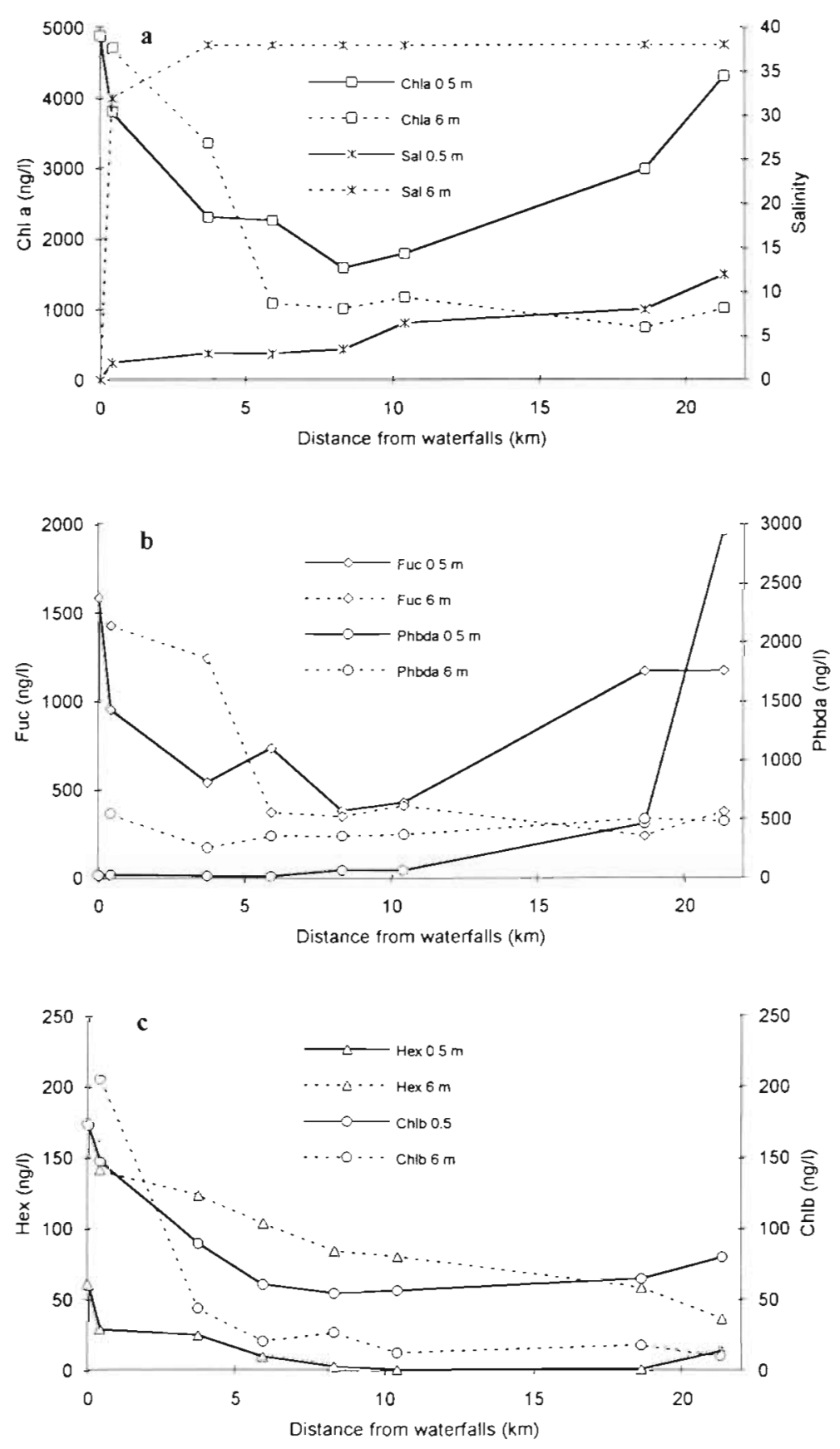

Fig. 4. Axial profiles of salinity, chl a and selected carotenoid and phaeophorbide concentrations in the Krka estuary (March 1991). Fuc: fucoxanthin; Phbda: phaeophorbide $a_{i}$ Hex: 19'-hexanoyloxyfucoxanthin; Chlb: chl $b$

layer, except for Stns E1 and E2, which are situated at the end of the salt wedge of the estuary $(0.4$ and $3.7 \mathrm{~km}$ from the waterfalls, respectively). In contrast, the concentrations of Hex in the brackish layer were low (1 to $35 \mathrm{ng}^{-1}$ ), indicating a low abundance of prymnesiophytes in that estuarine compartment. In the saline water layer, however, they represented the second most important phytoplankton group while the abundance of green algae was very low $\left(<30 \mathrm{ng}\right.$ chl $\left.b \mathrm{l}^{-1}\right)$. Consequently. the chl $b$ :Hex ratios (weight:weight) in brackish water (3.6 to 65) were quite different from those in the saline water $(0.16$ to 1.5).

The distribution of the degradation products of chl $a$, which are indicative of the physiological status of phytoplankton biomass and its transformation, revealed an interesting pattern which was significantly different from the profiles of chl $a$ and the other photosynthetic pigments. The most abundant chl a degradation product in the estuary was phaeophorbide a (16 to $18400 \mathrm{ng} \mathrm{l}^{-1}$ ), while chlorophyllide a (100 to $4800 \mathrm{ng} \mathrm{l}^{-1}$ ), pyrophaeophorbide a (11 to $449 \mathrm{ng} \mathrm{l}^{-1}$ ) and phaeophytin a (5 to $151 \mathrm{ng} \mathrm{l}^{-1}$ ) were less prominent. The main features of the distribution of phaeophorbide $a$ along the longest sector of the estuary were the rather low concentrations (14 to $68 \mathrm{ng} \mathrm{l}^{-1}$ ) at the freshwater end and in the brackish layer and the significantly higher, but rather uniform concentrations, in the saline layer (258 to $545 \mathrm{ng} \mathrm{l}^{-1}$ ) (Fig. 4b). An exception was the estuarine section between Stns E4A $(18.6 \mathrm{~km}$ from waterfalls) and $\mathrm{E} 5(21.3 \mathrm{~km}$ from waterfalls), situated close to the estuary mouth, where a very sharp increase in phaeophorbide a levels in brackish water was observed (505 to $2948 \mathrm{ng} \mathrm{l}^{-1}$ ). The phaeophorbide:chl a ratio in the brackish layer varied between 0.006 and 0.71 , increasing from the freshwater end to the marine end of the estuary, which indicated large variations in the physiological status and transformation processes of the phytoplankton. A much lower variability in this ratio $(0.077$ to 0.67$)$, but with a similar increasing trend towards the estuary mouth, was noted in the saline layer.

Depth profiles of chl $a_{\text {, carotenoids and }}$ phaeopigments for the lower part of the estuary (Šibenik Harbour, E4A) showed a unique pattern characteristic of highly stratified estuaries (Žutić \& Legović 1987) (Fig. 5). A very sharp halocline divided the estuary into 2 distinct layers. The brackish water layer (salinity 8 PSU) was characterised by a significantly higher chl a level than the underlying saline water layer The ratio of chl a concentrations at 0.5 and $6 \mathrm{~m}$ was $>4$ (Fig 5a). However, the maximum concentration of chl a was deter- 

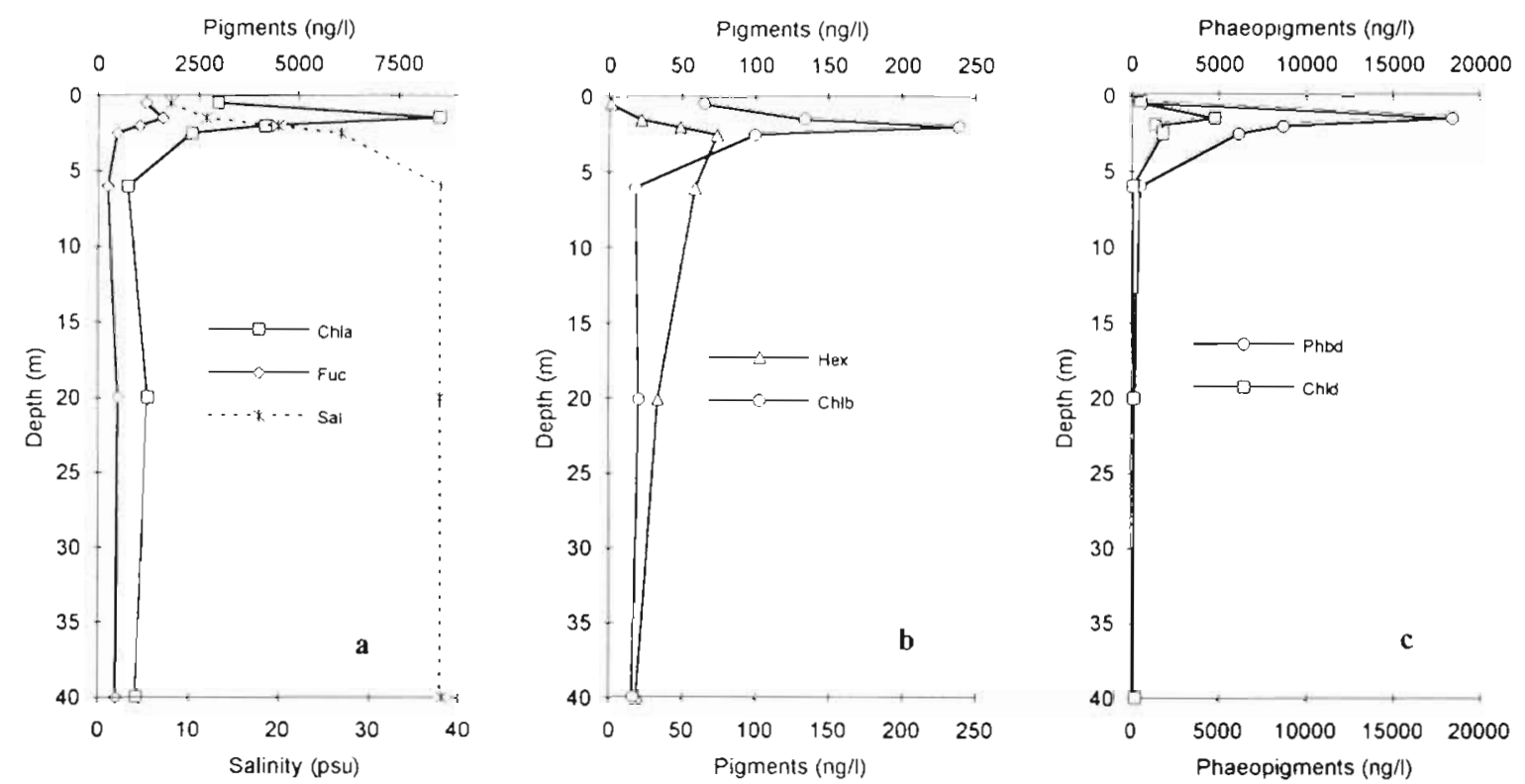

Fig. 5. Vertical profiles of salinity, chl $a$, and selected carotenoid and phaeopigment concentrations in the Krka estuary (at Stn E4A, March 1991). Chld: chlorophyllide a; all other pigments as in Fig. 4

mined in the upper part of the halocline $(1.5 \mathrm{~m})$, with values reaching $8.5 \mathrm{\mu g} \mathrm{l}^{-1}$. The vertical profile of the predominant accessory pigment, fucoxanthin, closely matched that of chl $a$, with some differences observed at the interface of the brackish and saline layers ( 1.5 to $2.5 \mathrm{~m}$ ). Furthermore, in the interfacial layer, enhanced abundances of green algae (chl b) and prymnesiophytes (Hex) was noted (Fig. 5b). One of the interesting features of the vertical profiles of the accessory pigments was the depth variation in their sub-surface maxima, which probably reflected different salinity tolerances of the various phytoplankton groups. The maxima for Fuc, chl $b$ and Hex were determined at the depths of $1.5,2.0$ and $2.5 \mathrm{~m}$, respectively, corresponding to salinities of 12,20 and 27 PSU.

Distinctive maxima in the upper part of the halocline $(1.5 \mathrm{~m})$ were also observed for the phaeopigments. The concentrations of phaeophorbide a (18400 $\left.\mathrm{ng} \mathrm{l}^{-1}\right)$ and chlorophyllide a $\left(4800 \mathrm{ng} \mathrm{l}^{-1}\right)$ in this interfacial layer were $37-40$ and $10-48$ times greater, respectively, than in either the upper brackish water or saline layer. The level of phaeophorbide $a$ in the halocline layer also exceeded the chl a concentration by a factor of 2 , while in the rest of the water column phaeopigments represented only a minor fraction $(<20 \%$ ) of chl arelated compounds.

Discussion. Stratified estuaries represent unique ecosystems which are most suitable for studying phytoplankton responses to environmental changes due to the rather broad range of key physico-chemical properties occurring within a relatively small geo- graphic area (Mantoura 1987, Žutić \& Legović 1987) By examining the distribution of photosynthetic pigments we were able to investigate the effect of salinity gradients, as well as different nutrient inputs, on phytoplankton dynamics in a permanently stratified estuarine environment.

Based on characteristic chemotaxonomic markers, 3 classes of phytoplankton were found to be important in the Krka estuary during a spring bloom: diatoms (Fuc), prymnesiophytes (Hex) and green algae (chl b), with diatoms being the strongly predominant group. The axial profiles for the various phytoplankton pigments provided a very good confirmation of the importance of the salinity boundary at 4-7 PSU as a critical region of physiological stress for freshwater species (Kinne 1971). The Krka estuary is fed by freshwater from Visovac Lake, and spring diatom blooms in the lake are dominated by 2 main species, Asterionella formosa and Cyclotella ocellata (Viličić et al. 1989, 1990). In March 1991, the salinity of the brackish layer was very low throughout the whole estuary $(<10$ PSU), and in the upper section it was even below 3.5 PSU (Fig. 2). Thus it was possible for freshwater phytoplankton to survive at longer distances from the head of the estuary. In the lower part of the estuary (Šibenik Harbour area), however, salinities $>8$ PSU were recorded in the brackish layer. Since freshwater phytoplankton do not survive at these higher salinities (Viličic et al. 1989), the diatoms in the lower estuary were composed mainly of estuarine species that have a high salinity tolerance. The most abundant species found in the 
Krka estuary at salinities $>8$ PSU are Chaetoceros sp., Nitzschia delicatissima and Skeletonema costatum (Viličić et al. 1989).

There seemed to be 3 distinct sources of nutrient input into the estuary (1) the Krka River, (2) remineralization of dying freshwater plankton and (3) wastewaters from the town of Sibenik. Freshwater being discharged into the estuary contained high levels of both nitrate and silicate (Fig 2) which sustained a relatively high phytobiomass in the brackish layer. In contrast, the levels in the underlying saline layer were very low

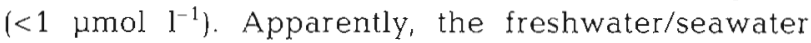
interface (FSI) is a very efficient barrier which prevents mixing of the 2 layers; therefore, the saline water was low in nutrients along the largest part of the axial profile (Legovic et al. 1994). An exception to this feature was at the end of the salt wedge $(0$ to $3.7 \mathrm{~km}$ from the waterfalls), where enhanced mixing with freshwater increased nutrient concentrations in the saline layer. In addition, greater levels of phaeopigments in the saline layer at the head of the estuary indicate that the decay of freshwater phytoplankton (Fig. 4) and remineralisation of this phytobiomass would have been an important secondary source of nutrients. The oxygen saturation in the saline layer of the salt wedge decreased to only $70 \%$ despite increased phytoplankton growth (Fig. 2)

Among different phytoplankton groups which responded to nutrient input by freshwater and/or remineralisation of decaying freshwater phytoplankton, diatoms seemed to be the most efficient, followed by green algae, while prymnesiophytes were the least affected (Fig. 4). This is in agreement with laboratory observations of nutrient enrichment experiments with phytoplankton from the northern Adriatic (Mozetic 1993) which showed that diatoms present in autochthonous plankton assemblages in early spring responded to river water additions comparatively faster than the other phytoplankton groups. A similar response by the 2 phytoplankton groups to additional nutrient input was observed in the lower part of the estuary where municipal wastewater from the town of Sibenik is discharged at $0.3 \mathrm{~m}^{3} \mathrm{~s}^{-1}$. It should be noted, however, that the new production triggered by the nutrient-rich wastewaters resulted in a sharp increase in phytobiomass only in the brackish layer, while the saline layer remained mostly unaffected. Such a distribution was the consequence of low nutrient levels in the saline layer $\left(<1 \mu \mathrm{mol} \mathrm{NO}_{3}{ }^{-} \mathrm{l}^{-1}\right)$ caused by stratification of the estuarine water column, which prevented. the introduction of wastewater-borne nutrients from. the upper layer. A similar conclusion was reached by Denant et al. (1991) based on a detailed pigment distribution in the Krka estuary in May 1988. Light attenuation could play some role in reducing phytoplankton production in the saline layer; however, since the suspended particulate matter (SPM) concentrations in both brackish and saline water layers are very low (<5 $\mathrm{mg} \mathrm{l}^{-1}$; Legovic et al. 1994), the effect is not expected to be very pronounced.

The axial and depth profiles of chl a breakdown products in the Krka estuary were found very useful for interpreting the physiological status and transformation patterns of phytobiomass. The most significant production of phaeopigments was observed in the lower part of the estuary (Fig. 5c). Phaeopigment levels at $6 \mathrm{~m}$ depth were always greater than those at $0.5 \mathrm{~m}$, but the maximum concentration was observed at the FSI (18.5 $\left.\mathrm{g} \mathrm{I} \mathrm{I}^{-1}\right)$ and exceeded the concentration of chl a by a factor of 2 . We suggest 3 possible mechanisms to explain this observation. The first is the massive mortality of freshwater phytoplankton between stations $\mathrm{E} 3$ and $\mathrm{E} 4 \mathrm{~A}$ as consequence of the increase in salinity from 6 to 8 PSU, which was exactly the salinity range identified as a critical region of physiological and osmotic stress for freshwater species (Kinne 1971). Secondly, a significant effect of grazing could be invoked since there is a large shellfish farming area in the estuarine section between the 2 stations; however, the ratios between phaeophorbide and pyrophaeophorbide concentrations in the upper layer, including the FSI, were very high (21 to 41$)$, indicating a rather low contribution of grazing (Head et al. 1994). The third is the existence of a very stable halocline which acts as a barrier to the efficient transport of particles into the underlying saline layer (Žutić \& Legović 1987).

Our results suggest that the phytobiomass was subject to intensive degradation processes at the brackish water/seawater interface, and that this interface was also an important region for the accumulation of senescent phytoplankton sinking down from the brackish layer. As a consequence, a large part of the organic matter produced in the brackish layer is not recycled within the estuary but flushed out in the adjacent coastal waters. This mechanism has a strong impact on carbon and nitrogen budgets, significantly reducing the trapping of these elements in the Krka estuary. Consequently, the eutrophication pressure triggered by relatively large and continuous nutrient inputs into the ecosystem by the Krka River and sewage discharges of the town of Sibenik is minimized.

Acknowledgements. This work was financially supported by a grant from the Commission of the European Communities (CI1/0147). The support of the Ministry of Science and Technology of the Republic of Croatia and the British Council through the Academic Links and Interchange Scheme (ALIS) is also gratefully acknowledged. We also thank Renata Kveštak for technical assistance, Damir Viličić for helpful discussions and Alenka Malej for critucally reading the manuscript. 


\section{LITERATURE CITED}

Barlow RG, Mantoura RFC, Gough MA, Fileman TW (1993a) Pigment signatures of the phytoplankton composition in the north eastern Atlantic during the 1990 spring bloom. Deep Sea Res Part II Top Stud Oceanogr 40:459-477

Barlow RG, Mantoura RFC, Gough MA, Fileman TW (1993b) Phaeopigment distribution during the 1990 spring bloom in the north eastern Atlantic. Deep Sea Res Part I Oceanogr Res Pap 40:2229-2242

Bianchi TS, Findlay S, Dawson R (1993) Organic matter sources in the water column and sediments of the Hudson River estuary: the use of plant pigments as tracers. Estuar Coast Shelf Sci 36:359-376

Bidigare RR, Marra J, Dickey TD, Iturriaga R, Baker KS, Smith RC, Pak H (1990) Evidence for phytoplankton succession and chromatic adaptation in the Sargasso Sea during spring 1985. Mar Ecol Prog Ser 60:113-122

Denant V, Saliot A, Mantoura RFC (1991) Distribution of algal chlorophyll and carotenoid pigments in a stratified estuary: the Krka River, Adriatic Sea. Mar Chem 32:285-298

Everitt DA, Wright SW, Volkman JK, Thomas DP, Lindstrom EJ (1990) Phytoplankton community compositions in the western equatorial Pacific determined from chlorophyll and carotenoid pigment distributions. Deep Sea Res 37:975-997

Gieskes WW, Kraay GW (1986) Floristic and physiological differences between the shallow and the deep nanoplankton community in the euphotic zone of the open tropical Atlantic revealed by HPLC analysis of pigments. Mar Biol 91:567-576

Hager A, Stransky H (1970) The carotenoid pattern and the occurrence of the light induced xanthophyll cycle in various classes of algae. V. A few members of Cryptophyceae. Euglenophyceae, Bacillariophyceae, Chrysophyceae and Phaeophyceae. Arch Microbiol 73:77-89

Head EJH, Hargrave BT, Subba Rao DV (1994) Accumulation of a phaeophorbide a-like pigment in sediment traps during late stages of a spring bloom: a product of dying algae? Limnol Oceanogr 39:176-181

This note was submitted to the editor
Kinne O (ed) (1971) Marine ecology, Vol 1, Environmental factors, Part 2. Wiley Interscience, London

Klein B, Sournia A (1987) A daily study of the diatom spring bloom at Roscoff (France) in 1985. Il. Phytoplankton pigment composition studied by HPLC analysis. Mar Ecol Prog Ser 37:265-275

Legović T, Žutić V, Gržetić Z, Cauwet G, Precali R (1994) Eutrophication in the Krka estuary. Mar Chem 46:203-215

Mantoura RFC (1987) Organic films at the halocline. Nature $328: 579-580$

Mantoura RFC, Llewellyn CA (1983) The rapid determination of algal chlorophyll and carotenoid pigments and their breakdown products in natural waters by reverse-phase high-performance liquid chromatography. Anal Chim Acta 151:297-314

Morris AW, Mantoura RFC, Bale AJ, Howland RJM (1978) Very low salinity regions of estuaries: important sites for chemical and biological reactions. Nature 274:678-680

Mozetic P (1993) The role of individual phytoplankton sizefractions in the biomass and primary production of the southern part of the Gulf of Trieste. MSc thesis, University of Zagreb, Croatia

Roy S (1989) HPLC-measured chlorophyll-type pigments during a phytoplankton spring bloom in Bedford Basin (Canada). Mar Ecol Prog Ser 55:279-290

Viličić D, Legović $T$, Žutić $V$ (1989) Vertical distribution of phytoplankton in a stratified estuary. Aquat Sci 51:31-46

Viličić D, Petricioli D, Jasprica N (1990) Seasonal distribution of phytoplankton in the Krka estuary and Visovac Lake. In: Kerovec M (ed) Ecological monographs, Vol 2. Croatian Ecological Society, Zagreb, p 317-330

Žutić V, Legovic T (1987) A film of organic matter at the freshwater/sea-water interface of an estuary. Nature 328: $612-614$

Žutić V. Legović T (1993) Eutrophication processes in the stratified Krka estuary (Adriatic Sea): importance of biogeochemical reactions at the halocline. Final Report, EEC Project CI1 'CT88-0333, Ruđer Bošković Institute, Zagreb, 1993, p 27

Manuscript first received: March 13, 1996

Revised version accepted: July 26, 1996 